\title{
Addressing Challenges in Humanistic Communication During COVID-19 Through Medical Education
}

\author{
Shefali Amin ${ }^{1,2 *}$, Justin Chin ${ }^{2,3}$, Mark A. Terrell ${ }^{1,2}$ and Christine M. Lomiguen ${ }^{1,2}$ \\ ${ }^{1}$ College of Osteopathic Medicine, Lake Erie College of Osteopathic Medicine, Erie, PA, United States, ${ }^{2}$ Graduate School of \\ Biomedical Sciences, Lake Erie College of Osteopathic Medicine, Erie, PA, United States, ${ }^{3}$ Department of Family Medicine, \\ Lifelong Medical Care, Richmond, CA, United States
}

OPEN ACCESS

Edited by: Mainul Haque,

National Defense University of Malaysia, Malaysia

Reviewed by: M.D. Bodrud-Doza, BRAC, Bangladesh Merryn McKinnon, Australian National University, Australia Keerti Singh, The University of the West Indies, Barbados Santosh Kumar

Gujarat University, India

*Correspondence: Shefali Amin samin46804@med.lecom.edu

Specialty section:

This article was submitted to Health Communication, a section of the journal Frontiers in Communication

Received: 20 October 2020 Accepted: 11 January 2021 Published: 12 February 2021

Citation:

Amin S, Chin J, Terrell MA and Lomiguen CM (2021) Addressing

Challenges in Humanistic Communication During COVID-19

Through Medical Education.

Front. Commun. 6:619348. doi: $10.3389 /$ fcomm.2021.619348
The current global pandemic due to COVID-19 has resulted in widespread lockdowns, social distancing, and other protective guidelines; these infectious control and mitigation measures challenge the medical system and create anxiety among all populations. In hospitals and healthcare facilities, patient interaction and shared decision making are sacrificed for fear of COVID-19 nosocomial spread. The intangible effects of human interaction with COVID-19 patients, whether of a physician or a patient's family, are replaced with isolation amid ventilators. Medical professionals must find a way to practice life-saving medical care while maintaining humanistic and professional interactions. This article provides insight into the necessity and challenges of humanistic communication during COVID-19 across various institutions and offers both short- and long-term solutions and reforms through medical education.

Keywords: medical education, COVID-19, humanism, pandemic, humanistic

\section{INTRODUCTION}

In March 2020, the Coronavirus disease 2019 (COVID-19) rapidly transitioned to a worldwide pandemic, significantly affecting both the general population and the medical community (Adams and Walls, 2020). As the virus spread, physicians were confronted with caring for infected patients, who were not only critically ill but also fearful of their potential mortality. In order to control nosocomial spread, infection precautions were implemented, such as isolating patients to confined rooms without family or friends and maintaining physical distancing by communicating with medical staff via phone or video (Sonis et al., 2020). For healthcare providers required to enter the room for assessment and delivery of care, the utilization of personal protective equipment (PPE), including but not limited to masks, shields, gowns, and gloves, was essential for safety (Adams and Walls, 2020). From an institutional standpoint, these precautions were necessary to limit spread of the virus within the facility. To patients and providers, these restrictions caused a significant emotional toll (Sonis et al., 2020). Patients' anxiety and fear of the virus heightened when unable to recognize providers covered head-to-toe in protective gear. Physicians were exhausted under layers of PPE, overworked due to increased demand in critical care and infected patients, and worried about how they were to take care of their patients in this unfamiliar setting (Sonis et al., 2020). 


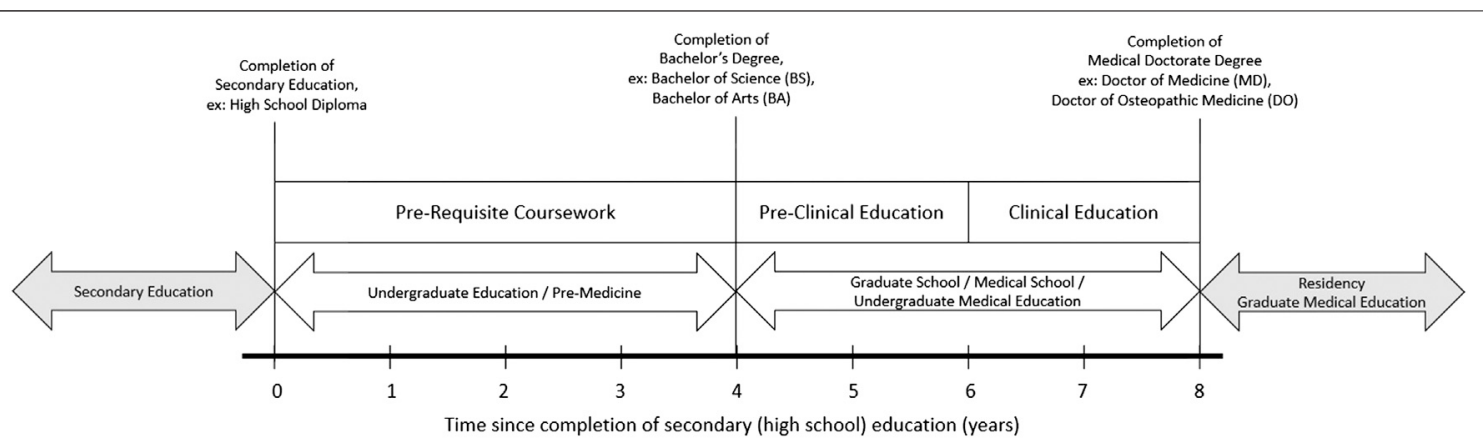

FIGURE 1 | Medical Education Framework - In the United States, traditionally, completion of high school (secondary school) education and the awarding of the high school diploma or equivalent is followed by four years of education at an undergraduate school; this is commonly known as "pre-medicine," as it requires prerequisite coursework for education at a graduate school, specifically "medical school" for those whose intent is to become a physician, and ends with the completion of a bachelor's degree or equivalent. Subsequently, medical school, also known as undergraduate medical education, is divided into two years of pre-clinical education followed by two years of clinical education, totaling four years, and culminating in the earning of the medical doctorate degree, either the doctor of medicine (MD) or doctor of osteopathic medicine (DO) degree. In most instances, one must continue to residency, also known as graduate medical education, after the completion of medical school, varying in length based on specialty, to meet qualifications for a license to practice medicine.

\section{MEDICAL EDUCATION}

\section{Medical Education Framework}

It is important to focus on medical education in the midst of a pandemic because of its direct influence on the training of future physicians; progressive and innovative curricular modifications can positively impact the development of future healthcare heroes while disruptions could lead to drastic effects on patients and the communities which physicians serve. In the United States, the traditional four-year medical education curriculum (medical school, or "med school") begins after completion of a bachelor's degree and necessary pre-requisite coursework (premedicine, or "pre-med"), with the first two years in the classroom or lecture hall to acquire fundamental basic science and clinical knowledge, designated as "pre-clinical" education, and the last two years spent in hospitals and various clinical training sites, transitioning every two to eight weeks to a different specialty, known as "rotations" within "clinical" education (Figure 1). Preclinical students accustomed to instruction in large lectures or peer interaction in smaller classrooms are now taught virtually through live-streamed or recorded lectures to decrease risk of infection spread and to safely practice social distancing (Samarasekera et al., 2020; Singh et al., 2020); this led to a direct impact in medical schools utilizing laboratories and cadavers for dissection in first-year anatomy and introductory history and physical examination courses, requiring a shift to a digital platform. Clinical students were removed from in-person rotations and provided an online curriculum, due to the risks of contracting the virus and either becoming ill or remaining asymptomatic and acting as carriers, or spreaders, of the disease (Rose, 2020). Adaptations were rapidly made for the delivery of medical education.

The clinical years are typically thought of as the formative years of a medical student's journey (Holden et al., 2012; Gaufberg et al., 2017). Rotations allow students to physically immerse themselves in different medical specialties and discover their professional identity. Their experiences in hospitals and healthcare centers, being part of a patient's care team, learning clinical skills, and collaborating directly with physicians is not something that can be entirely reproduced online (Rose, 2020). Yet, in late Spring 2020, medical schools had no choice given the severity of the pandemic. Medical students were also challenged with the cancellations of licensure examinations, required for continuing to graduate medical education, or residency, after medical school. While these adjustments in medical education may seem minor compared to the worldwide effect of the pandemic, their implications on the training of medical students is yet to be measured. With limited time to provide a substitute online curriculum, it is still unknown whether the lack of clinical experience, as well as lack of patient interaction during times of uncertainty, could affect the student's future humanistic performance in residency and beyond (Ferrel and Ryan, 2020).

\section{Humanism in Medical Education and Practice}

Medicine was founded on the responsibility of establishing a strong physician-patient relationship, through verbal and nonverbal communication. The physician's role was simple: to benefit the patient by bringing science and humanism together (Schwenk, 2020). Humanism is defined as actions and attitudes of physicians which address not only concerns but also values of patients, showing both respect for and interest in patients (Branch et al., 2001). Similar to professionalism, humanism is considered an essential component in medical education. A physician embodies humanistic values when the patients' social, cultural, spiritual, and emotional experiences are taken into consideration when providing care (Lomiguen et al., 2020). With humanistic care, there is respect and dignity toward both parties as well as compassion and communication (Cohen and Sherif, 2014). Modern medicine and the public health system have challenged humanism by giving physicians more responsibility and more commitments, making it difficult to prioritize the patient. With the rise of scholarly activity 
requirements, lab orders, and dependence on technology, medicine has shifted toward "dehumanization in care" with resultant patient dissatisfaction (Gorlin and Zucker, 1983). Physicians now spend more than half their time documenting, or "charting," on computers rather than using that time engaging and enhancing patient care (Schwenk, 2020). Despite technology emerging as a way to help physicians provide greater and more efficient care for their patients, it has turned into a distraction from patient interaction (Gorlin and Zucker, 1983). Before the pandemic, physicians were burdened with increasing tasks and demands and facing burnout (West et al., 2018; Thuma et al., 2020). Challenges and pressures led physicians to diminish humanistic practices to compensate for the amount of time required for additional responsibilities (Cohen and Sherif, 2014). It took a worldwide pandemic to remind healthcare workers of the necessity of humanism and professionalism through the "nature of suffering and the fragility of life" (Benatar and Daneman, 2020).

While humanism is taught in medical schools, its current emphasis is insufficient. Past studies have provided some evidence that suggests adding professional and humanistic aspects of medicine is effective in medical school (Cohen, 2007); however, medical students are critical of how they are taught (Haidet et al., 2001; Lypson and Hauser, 2002). In recent years, a contributing factor in teaching medical students humanism is for high pass rates on medical licensure examinations, or "board exams," in addition to learning to foster patient relationships. In 2005, the National Board of Osteopathic Medical Examiners (NBOME) established the Comprehensive Osteopathic Medical Licensing Examination of the United States Level 2 Physical Examination, abbreviated COMLEX-United States Level 2 PE, a practical examination in which fundamental clinical skills assessed are categorized into one of two domains: the Biomedical/Biomechanical Domain and the Humanistic Domain. The Humanistic Domain is inclusive of physician-patient communication, interpersonal skills, and professionalism (National Board of Osteopathic Medical Examiners, 2020). Achieving humanistic competency is essential, as poor communication between physicians and patients is a detriment to healthcare, decreasing quality and increasing costs of care (Institute of Medicine, 2001; Frankel, 2006). However, medical students may face a disconnect in humanism when they enter clinical years through exposure to poor professional behavior by other members of the healthcare team (Jones et al., 2004; Huggett et al., 2008). The result is that many medical students view humanism as a requirement to pass their board exams, but not a requirement for a practicing physician. Moreover, the humanistic ideals are further lost as medical students transition to residents because residency programs may not emphasize humanism. Therefore, it is necessary to have proper humanistic curricula in the preclinical and clinical years of undergraduate medical education as well as in graduate medical education to foster change that can lead to life-long practice changes in healthcare.

The pandemic revealed the need for interpersonal skills for the healing process and positive patient outcomes. As students, residents, and physicians begin to embrace humanism in practice, the future of health care will greatly improve (Benatar and Daneman, 2020). This paper offers three shortterm strategies to include in medical education to encourage humanism in medical practice during the pandemic: effective physician-patient communication, telemedicine, and empathetic techniques. Long-term strategies include suggested requirements in humanism for institutional assessment and evaluation as well as for continuing medical education, board certification, and licensing renewal.

\section{DISCUSSION}

\section{Encouraging Humanism During the Pandemic}

First, effective physician-patient communication is of the utmost importance during the pandemic. Therefore, it is important to teach medical students the humanistic ideal of presence, which refers to "aspects of awareness, acceptance, availability, and expressiveness" (Hoffman, 2020). Presence involves the physician and patient recognizing the role of one another and building a trusting relationship. During times of uncertainty, such as a pandemic, it is crucial that this step not be diminished. Establishing a meaningful relationship is significant because it gives the patient a sense of safety and commitment for long-term follow-up care (Hoffman, 2020). Additionally, the physical presence of healthcare workers, much like gloves, masks, hand sanitizers, and ventilators, was of increased value and demand, as healthcare worker shortages were pronounced during the pandemic (Adams and Walls, 2020). This was further exacerbated at the height of the COVID-19 pandemic when medical students assisting in hospitals were removed from inperson rotations for safety and placed under stay-at-home orders with the rest of the general population. Students felt the chaos in the general population but were unable to witness the emotional trauma felt by patients as well as the gravity of meaningful physician presence and patient communication. As medical students can feel overwhelmed with the vast amount of factual basic science and clinical knowledge they must learn, it is important for curricula to include coursework and lessons on effective physician-patient communication, ideally with the use of live practice patients, also known as standardized patients. Assessments should also serve to evaluate effective communication, rather than the mere regurgitation of facts. Teaching students the importance of presence in everyday medicine will create more humanistic physicians.

Second, training on telemedicine practices is imperative. During the COVID-19 pandemic, practicing social distancing and keeping safe from contracting the virus has meant only seeing patients in-person when necessary (Jnr, 2020). To continue seeing patients, physicians began to rely on telehealth. Although telehealth is a technology-based patient encounter, its use throughout the pandemic has demonstrated advancement of technology does not necessarily require medicine to be dehumanized (Stimell-Rauch et al., 2020). Despite telehealth seeming distant and removing the traditional history, physical examination, and other entities of the physician-patient in- 
person interaction, the connections established virtually can feel intimate in that it is unrushed and without external distractions. Telehealth can have a meaningful impact on a patient's life, especially during times of isolation. The physician's role in telehealth remains the same: to establish a physician-patient relationship and to guide patients through their care (StimellRauch et al., 2020). While technology and humanism are separate entities for consideration, there exists a relationship, where one needs the other to function properly. In both undergraduate and graduate medical education, medical students and residents, respectively, should practice forging relationships via telehealth by occasionally scheduling virtual encounters with their outpatient follow up visits. As students are re-integrated in the clinical field, they should also attempt to view or participate in virtual encounters. Pre-clinical students are taught how to conduct a proper in-person history and physical examination prior to beginning rotations. In the future, it will be necessary to simultaneously teach students how to perform a virtual patient encounter. As the use of telehealth continues to increase, residents and medical students should become familiar with virtual patient encounters.

Third, an emphasis on empathic communication techniques are especially needed to comfort patients in-person or in virtual patient encounters during the pandemic. For example, a useful humanistic mnemonic to use in both settings is ICARE, which stands for Introduction, Collaboration, Acknowledgment, Reflection, Expectations. All members of the care team should introduce themselves and their role in care to the patient, and this may need to be done every time they interact with the patient. The physician should also remember to acknowledge the emotions surrounding the situation and engage in reflective listening. Lastly, the physician should convey the plan and expectations for the patient throughout their time together (Sonis et al., 2020). Previous studies have shown the effectiveness of role-playing and improvisation exercises in teaching medical students clear and empathetic communication (Kaplan-Liss et al., 2018). Thus, medical education at all levels should aim to modify existing curricula and training to include an emphasis on humanism. Medical schools should consider teaching the ICARE mnemonic and similar tools for humanistic communication to students during their pre-clinical years, possibly as part of their clinical skills curriculum and/or in small group settings, and students should continue practicing its use during their clinical rotations. Practicing physicians should be taught, during in-house training sessions and other continuing medical education opportunities, and reminded to incorporate the ICARE mnemonic in their practice. Use of the ICARE mnemonic in daily practice has the potential to increase compassionate communication with patients.

Empathy and other components of humanistic communication has been recently reported as beneficial for both physicians and patients (Pohontsch et al., 2018; Abrams et al., 2020). Medical student interviews resulted in the identification of hands-on experiences and highlighting the importance of empathy as major influences in the professional development and empathetic communication and expression (Pohontsch et al., 2018). Thus, the aforementioned small group activities, roleplaying and improvisation exercises, and inclusion of techniques for improved physician-patient humanistic communication within graded and/or required coursework to emphasize its importance can be incorporated into curriculum for focused training.

Though short-term strategies with emphasis on effective physician-patient communication, telemedicine, and empathetic techniques are encouraged, long-term strategies also must be considered for the development of humanistic communication in medical practice. While introductory lessons in undergraduate medical education are important, humanistic communication should be emphasized as a necessity, not an option, for clinical practice, at all times, not solely for implementation during a global health pandemic due to increased physical distance, addition of barriers for infectious control, and scarcity of resources. Suggested long-term strategies include humanistic requirements for 1) institutional assessment and evaluation, for example, as included criteria in quarterly or yearly departmental reviews by supervisors or organizational human resources, 2) continuing medical education, and 3) board certification and licensure, for physicians obtaining them initially or for renewal of credentials.

\section{CONCLUSION}

As physicians provide medical care to patients during the COVID19 pandemic, emphasizing compassion and humanism is needed more than ever. Adding humanism to patient care is not burdensome or time consuming, and may improve patient care and personal satisfaction, especially during challenging times. By highlighting humanism in everyday practice, physicians may be more resilient when facing stressors, such as those imposed by a global health pandemic (Sonis et al., 2020). The earlier humanism is introduced in a person's medical career, such as medical school and residency, the more natural, habitual, and automatic its implementation will be in physicians. High quality medical care lies in providing both clinical skills and representing humanistic ideals (Benatar and Daneman, 2020). Though unexpected, the pandemic brought about changes in humanism and these proposed curriculum additions for undergraduate medical education for students, graduate medical education for residents, and even continuing medical education for practicing physicians that will benefit patients forever (Sonis et al., 2020).

Behaviors linked to humanistic care include: demonstrating respect, enhancing personal connections, invoking and responding to emotional expressions, identifying humanistic behaviors, and illustrating self-awareness in practicing humanistic care. The COVID-19 pandemic calls for new innovations in curricular delivery, including bedside teaching, improvements in empathy, and improved patient communication, both at the undergraduate and graduate medical education levels. Limitations include the challenges of implementing and assessing humanistic communication with pandemic precautions in place. Future studies can consider measuring the effectiveness of implementing humanistic curricular components with qualitative analysis of written evaluations or quantitative analysis of grades, constituents of licensure examination scores, or with the utilization of various scales developed to assess empathy, such as the Basic Empathy 
Scale in Adults (BES-A), the Hogan Empathy Scale, or the Jefferson Scale of Physician Empathy (Jolliffe and Farrington, 2006; Cross and Sharpley, 1982; Hojat et al., 2001), which previously have been used in recent, small-scale studies in medical education prior to the COVID-19 pandemic (Newton et al., 2000; Evans et al., 1993; Batt-Rawden et al., 2013).

\section{AUTHOR CONTRIBUTIONS}

All authors listed have made a substantial, direct, and intellectual contribution to the work and approved it for publication.

\section{REFERENCES}

Abrams, M. P., Eckert, T., Topping, D., and Daly, K. D. (2020). Reflective writing on the cadaveric dissection experience: an effective tool to assess the impact of dissection on learning of anatomy, humanism, empathy, well-being, and professional identity formation in medical students. Anat. Sci. Educ. [Epub ahead of print]. doi:10.1002/ase.2025

Adams, J. G., and Walls, R. M. (2020). Supporting the health care workforce during the COVID-19 global epidemic. Jama 323 (15), 1439-1440. doi:10.1001/jama.2020.3972

Batt-Rawden, S. A., Chisolm, M. S., Anton, B., and Flickinger, T. E. (2013). Teaching empathy to medical students: an updated, systematic review. Acad. Med. 88 (8), 1171-7. doi:10.1097/ACM.0b013e318299f3e3

Benatar, S., and Daneman, D. (2020). Disconnections between medical education and medical practice: a neglected dilemma. Glob. Public Health 15 (9), 1292-1307. doi:10.1080/17441692.2020.1756376

Branch, W. T., Jr, Kern, D., Haidet, P., Weissmann, P., Gracey, C. F., Mitchell, G., et al. (2001). The patient-physician relationship. teaching the human dimensions of care in clinical settings. J. Am. Med. Assoc. 286 (9), 1067-74. doi:10.1001/jama.286.9.1067

Cohen, J. J. (2007). Viewpoint: linking professionalism to humanism: what it means, why it matters. Acad. Med. 82 (11), 1029-32. doi:10.1097/01.ACM. 0000285307.17430 .74

Cohen, L. G., and Sherif, Y. A. (2014). Twelve tips on teaching and learning humanism in medical education. Med. Teach. 36 (8), 680-4. doi:10.3109/ 0142159X.2014.916779

Cross, D. G., and Sharpley, C. F. (1982). Measurement of empathy with the hogan empathy scale. Psychol. Rep. 50, 62. doi:10.2466/pr0.1982.50.1.62

Evans, B. J., Stanley, R. O., and Burrows, G. D. (1993). Measuring medical students' empathy skills. Br. J. Med. Psychol. 66 (Pt 2) (2), 121-33. doi:10.1111/j.20448341.1993.tb01735.x

Ferrel, M. N., and Ryan, J. J. (2020). The impact of COVID-19 on medical education. Cureus 12 (3), e7492. doi:10.7759/cureus.7492

Frankel, R. M. (2006). Pets, vets, and frets: what relationship-centered care research has to offer veterinary medicine. J. Vet. Med. Educ. 33 (1), 20-7. doi:10.3138/ jvme.33.1.20

Gaufberg, E., Bor, D., Dinardo, P., Krupat, E., Pine, E., Ogur, B., et al. (2017). In pursuit of educational integrity: professional identity formation in the Harvard Medical School Cambridge integrated clerkship. Perspect. Biol. Med. 60 (2), 258-274. doi:10.1353/pbm.2017.0032

Haidet, P., Dains, J. E., Paterniti, D. A., Chang, T., Tseng, E., and Rogers, J. C. (2001). Medical students' attitudes toward patient-centered care and standardized patients' perceptions of humanism: a link between attitudes and outcomes. Acad. Med. 76 (10), S42-4. doi:10.1097/00001888-200110001-00015

Gorlin, R., and Zucker, H. D. (1983). Physicians' reactions to patients. a key to teaching humanistic medicine. N. Engl. J. Med. 308 (18), 1059-63. doi:10.1056/ NEJM198305053081804

Hoffman, L. (2020). Existential-humanistic therapy and disaster response: lessons from the COVID-19 pandemic. J. Humanist. Psychol. 61 (1), 33-54. doi:10. $1177 / 0022167820931987$

Hojat, M., Mangione, S., Nasca, T. J., Cohen, M. J. M., Gonnella, J. S., Erdmann, J. B., et al. (2001). The Jefferson scale of physician empathy: development and

\section{FUNDING}

The authors declare that there is no external funding or financial support for this manuscript.

\section{ACKNOWLEDGMENTS}

The authors would like to acknowledge Silvia M. Ferretti, DO, Provost, Senior Vice President, and Dean of Academic Affairs of Lake Erie College of Osteopathic Medicine, for her support of the Master of Science in Medical Education program.

preliminary psychometric data. Educ. Psychol. Meas. 61 (2), 349-365. doi:10. $1177 / 00131640121971158$

Huggett, K. N., Warrier, R., and Maio, A. (2008). Early learner perceptions of the attributes of effective preceptors. Adv. Health Sci. Educ. Theory Pract. 13 (5), 649-58. doi:10.1007/s10459-007-9069-z

Institute of Medicine (2001). Crossing the qualih; chasm: a new health System for the 21st century. Washington, DC, United States: National Academies Press.

Jnr, B. A. (2020). Use of telemedicine and virtual care for remote treatment in response to COVID-19 pandemic. J. Med. Syst. 44 (7), 1-9. doi:10.1007/s10916020-01596-5

Jolliffe, D., and Farrington, D. P. (2006). Development and validation of the basic empathy scale. J. Adolesc. 29 (4), 589-611. doi:10.1016/j.adolescence.2005.08.010

Jones, W. S., Hanson, J. L., and Longacre, J. L. (2004). An intentional modeling process to teach professional behavior: students' clinical observations of preceptors. Teach. Learn. Med. 16 (3), 264-269. doi:10.1207/s15328015tlm1603_8

Kaplan-Liss, E., Lantz-Gefroh, V., Bass, E., Killebrew, D., Ponzio, N. M., Savi, C., et al. (2018). Teaching medical students to communicate with empathy and clarity using improvisation. Acad. Med. 93 (3), 440-443. doi:10.1097/ACM. 0000000000002031

Lypson, M. L., and Hauser, J. M. (2002). Talking medicine: a course in medical humanism--what do third-year medical students think?. Acad. Med. 77 (11), 1169-1170. doi:10.1097/00001888-200211000-00038

National Board of Osteopathic Medical Examiners (2020). COMLEX-United States level 2-PE. Available at:https://www.nbome.org/exams-assessments/ comlex-usa/comlex-usa-level-2-pe/. Accessed June 3, 2020

Newton, B. W., Savidge, M. A., Barber, L., Cleveland, E., Clardy, J., Beeman, G., et al. (2000). Differences in medical students' empathy. Acad. Med. 75 (12), 1215. doi:10.1097/00001888-200012000-00020

Lomiguen, C. M., Rosete, I., and Chin, J. (2020). Providing culturally competent care for COVID-19 intensive care unit delirium: a case report and review. Cureus 12 (10), e10867. doi:10.7759/cureus.10867

Pohontsch, N. J., Stark, A., Ehrhardt, M., Kötter, T., and Scherer, M. (2018). Influences on students' empathy in medical education: an exploratory interview study with medical students in their third and last year. BMC Med. Educ. 18 (1), 231-239. doi:10.1186/s12909-018-1335-7

Rose, S. (2020). Medical student education in the time of COVID-19. J. Am. Med. Assoc. 323 (21), 2131-2132. doi:10.1001/jama.2020.5227

Samarasekera, D. D., Goh, D. L. M., and Lau, T. C. (2020). Medical school approach to manage the current COVID-19 crisis. Acad. Med. 95 (8), 1126-1127. doi:10. 1097/ACM.0000000000003425

Schwenk, T. L. (2020). What does it mean to be a physician?. Jama 323 (11), 1037-1038. doi:10.1001/jama.2020.0146

Singh, K., Srivastav, S., Bhardwaj, A., Dixit, A., and Misra, S. (2020). Medical education during the COVID-19 pandemic: a single institution experience. Indian Pediatr. 57 (7), 678-679. doi:10.1007/s13312-020-1899-2

Sonis, J. D., Kennedy, M., Aaronson, E. L., Baugh, J. J., Raja, A. S., Yun, B. J., et al. (2020). Humanism in the age of COVID-19: renewing focus on communication and compassion. West. J. Emerg. Med. 21 (3), 499-502. doi:10.5811/westjem. 2020.4.47596

Stimell-Rauch, M., Szalay, L. R., and Bregstein, J. (2020). Telehealth and humanism: unexpected partnership forged during COVID-19. Emerg. Med. J., 37, 591-592. doi:10.1136/emermed-2020-209989 
Thuma, T., Lawandy, M., Lotfalla, A., Terrell, M., and Lomiguen, C. (2020). Mental health matters: mental health and overall well-being among first- and secondyear medical students. Health Prof. Educ. 6 (4), 516-521. doi:10.1016/j.hpe. 2020.07.003

Holden, M., Buck, E., Clark, M., Szauter, K., and Trumble, J. (2012). Professional identity formation in medical education: the convergence of multiple domains. HEC Forum 24 (4), 245-55. doi:10.1007/s10730-012-9197-6

West, C. P., Dyrbye, L. N., and Shanafelt, T. D. (2018). Physician burnout: contributors, consequences and solutions. J. Intern. Med. 283 (6), 516-529. doi:10.1111/joim.12752
Conflict of Interest: The authors declare that the research was conducted in the absence of any commercial or financial relationships that could be construed as a potential conflict of interest.

Copyright (c) 2021 Amin, Chin, Terrell and Lomiguen. This is an open-access article distributed under the terms of the Creative Commons Attribution License (CC BY). The use, distribution or reproduction in other forums is permitted, provided the original author(s) and the copyright owner(s) are credited and that the original publication in this journal is cited, in accordance with accepted academic practice. No use, distribution or reproduction is permitted which does not comply with these terms. 